\title{
Effects of substitution of tricaproin for tallow and of protein concentration in milk substitutes on nitrogen and energy balance in the preruminant lamb
}

\author{
BY BERNARD AUROUSSEAU \\ I.N.R.A., C.R.Z.V. de THEIX, Laboratoire d'Etude du Métabolisme Energétique, 63122 \\ Ceyrat, France
}

(Received 24 April 1987 - Accepted 17 May 1988)

\begin{abstract}
1. Results of 138 nitrogen balance studies from experiments with forty male Limousin and nineteen male Ile de France preruminant lambs were used to estimate total $\mathrm{N}$ requirements and to assess the effects of dietary tricaproin inclusion, protein concentration, lysine and methionine supplementation and the age of lambs on protein retention. In addition, energy balances were obtained in twenty-four of the Limousin lambs from birth up to 3 weeks of age by means of a slaughter technique.

2. For milk substitute unsupplemented with amino acids, tricaproin inclusion increased $\mathrm{N}$ balance slightly $(P<0.001)$ when a medium-protein concentration $(260 \mathrm{~g} / \mathrm{kg}$ dry matter $(\mathrm{DM}))$ was used, in 2-week-old lambs $(+4 \cdot 3 \%)$ and in 5 -week-old Limousin lambs $(+5 \cdot 3 \%)$, or very markedly when a high-protein concentration $(320 \mathrm{~g} / \mathrm{kg} \mathrm{DM})$ was used, in 2-week-old lambs $(+14.5 \%)$ and in 5-week-old lambs $(+18 \cdot 6 \%)$. Protein requirements decreased from $300 \mathrm{~g} / \mathrm{kg} \mathrm{DM}$ in 3-week-old lambs to $270 \mathrm{~g} / \mathrm{kg} \mathrm{DM}$ in 5 -week-old lambs for the control milk containing tallow-coconut oil mixture ( $0.67: 0.33$ by wt) and was increased above $300 \mathrm{~g} / \mathrm{kg} \mathrm{DM}$ at all ages in the case of experimental milk containing tallow-coconut oil-tricaproin mixture $(0 \cdot 33: 0 \cdot 33: 0 \cdot 33$, by $w t)$.

3. For milk containing either a medium- or a high-protein concentration and supplemented with lysine and methionine, inclusion of tricaproin increased $N$ balance $(P<0.01)$ to a similar extent $(+8.5$ up to $+14.3 \%)$ in 1 to 2- and 3-week-old Limousin lambs. An increase in N concentration in the milk had no effect in 1- and 2-weekold lambs, but led to a decreased $\mathrm{N}$ balance in 3-week-old lambs. Protein requirements decreased from $310 \mathrm{~g} / \mathrm{kg}$ $\mathrm{DM}$ in 1-week-old lambs to $190 \mathrm{~g} / \mathrm{kg} \mathrm{DM}$ in 3-week-old lambs for the milk containing tallow-coconut oil or from $300 \mathrm{~g} / \mathrm{kg} \mathrm{DM}$ in 2-week-old lambs to $210 \mathrm{~g} / \mathrm{kg} \mathrm{DM}$ in 3-week-old lambs for the milk containing tallowcoconut oil-tricaproin.

4. For the Ile de France lambs given milk supplemented with lysine and methionine, tricaproin inclusion did not alter $\mathrm{N}$ balance. Protein requirements decreased from $370 \mathrm{~g} / \mathrm{kg} \mathrm{DM}$ in 2-week-old lambs to $270 \mathrm{~g} / \mathrm{kg} \mathrm{DM}$ in 4-week-old lambs for milk containing both kinds of fat mixtures.

5. Between birth and 3 weeks of age, efficiency of metabolizable energy (ME) utilization in the Limousin lambs was not dependent on the nature of the milk fat or the protein concentration of the diet (ME efficiency for tissue deposition varying from 0.672 to 0.698 ) whilst ME efficiency for protein deposition was 0.52 and ME efficiency for lipid deposition was close to 1 ; daily maintenance expenditure was $553 \mathrm{~kJ} / \mathrm{kg}$ body-weight ${ }^{0.75}$.
\end{abstract}

Despite much research, the efficiency of medium-chain fatty acids in the utilization of energy for growth has still not been accurately determined. Substitution of tricaprylin $\left(C_{8}\right)$ or tricaproin $\left(\mathrm{C}_{6}\right)$ for equal amounts of energy from starch in the diet of young growing rats leads, in most instances, to reduced tissue energy deposition (Vermorel \& Aurousseau, 1970; Aurousseau, 1971; Aurousseau et al. 1978). Reduced tissue energy deposition after tricaprylin intake has also been observed in the piglet (Newport et al. 1979) and in the rat (Lavau \& Hashim, 1978). Nevertheless, some authors have observed a similar energy efficiency of caprylic acid and lauric acid utilization in rats of $35-340 \mathrm{~g}$ body-weight (Demarne et al. 1978), and an increased tissue energy deposition after substitution of tricaproin for starch in the diet offered to growing rats of $80-200 \mathrm{~g}$ body-weight (Chenat et al. 1976).

In the lamb digestibilities of dry matter (DM) $(0.984 v .0 .961)$, energy $(0.983 v .0 .956)$ and nitrogen $(0.970$ v. 0.955$)$ were significantly higher $(P<0.05)$ for the milk containing tallow-coconut oil-tricaproin mixtures at 1 and 2 weeks of age (Aurousseau et al. $1983 \mathrm{~b}$ ). 
Feed conversion efficiency (Aurousseau, 1984) was also greater $(P<0.05)$ after tricaproin inclusion (48.8 v. $40.6 \mathrm{~g}$ gain/MJ gross energy).

In the preruminant calf, neither tricaprylin (Aurousseau et al. 1984) nor tricaproin (Aurousseau et al. 1983 a) inclusion in the diet significantly altered tissue energy deposition despite a significant increase in tissue protein deposition (about $+10 \%$ ). We report here the results obtained from three trials which combine studies of the effects of tricaproin inclusion in a milk substitute at two protein concentrations, with or without supplementation of the milk with lysine and methionine, and in two breeds of lamb.

\section{EXPERIMEN TAL}

The detailed compositions of the milk substitutes are given in Table 1. According to the experimental design (Table 2) the main characteristics of the milk substitutes were as follows.

Trial 1. Four different spray-dried milks (CM1, CH1, TM1, TH1) combining two levels of protein concentration and two different types of lipids were prepared. Fish concentrate $(90 \mathrm{~g} / \mathrm{kg} \mathrm{DM})$ was introduced together with skim-milk powder $(570 \mathrm{~g} / \mathrm{kg} \mathrm{DM})$ in the milk substitutes to obtain a high-protein concentration $(\mathrm{H})$, i.e. $315 \mathrm{~g}$ protein $/ \mathrm{kg} \mathrm{DM}$. Whey powder $(225 \mathrm{~g} / \mathrm{kg} \mathrm{DM})$ was then substituted for part of the skim-milk powder to obtain a medium-protein level (M), i.e. $250 \mathrm{~g}$ protein $/ \mathrm{kg}$ DM. Tallow $(160 \mathrm{~g} / \mathrm{kg} \mathrm{DM})$ and coconut oil $(90 \mathrm{~g} / \mathrm{kg} \mathrm{DM})$ were introduced in the control diet (C) whilst $90 \mathrm{~g}$ tricaproin $/ \mathrm{kg} \mathrm{DM}$ was substituted for part of the tallow to obtain the $\mathrm{C}_{6}$ diets $(\mathrm{T})$, the lower energy concentration of tricaproin (i.e. 31.6 v. $38.5 \mathrm{~kJ} / \mathrm{g}$ ) being taken into account. However, part of the tricaproin floated in the reconstituted milk and was left in the refusals so that the true intake of $\mathrm{C}_{6}$ acid by the lambs was only $45 \mathrm{~g} / \mathrm{kg} \mathrm{DM}$ and the lipid concentration of the corresponding milks decreased to $210 \mathrm{~g} / \mathrm{kg} \mathrm{DM}$ and their protein content increased to 269 and $329 \mathrm{~g} / \mathrm{kg} \mathrm{DM}$.

Trials 2 and 3. Four different milks (CM2, CH2, TM2, TH2) supplemented with lysine and methionine were prepared, combining two concentrations of protein and two types of lipids. High-protein milk $(\mathrm{H})$ contained $145 \mathrm{~g}$ whey protein $/ \mathrm{kg}$ DM and $570 \mathrm{~g}$ skim-milk powder $/ \mathrm{kg}$ DM ; medium-protein milk (M) was obtained by substituting lactose $(137 \mathrm{~g} / \mathrm{kg}$ $D M)$ for the whey protein. Supplements of lysine $(6 \cdot 1 \mathrm{~g} / \mathrm{kg} \mathrm{DM})$ and methionine $(2: 2 \mathrm{~g} / \mathrm{kg}$ $\mathrm{DM}$ ) were added to $\mathrm{CH} 2$ and $\mathrm{TH} 2$ milks, to meet the requirements of the lambs as described by Patureau-Mirand \& Theriez (1977); higher supplements of lysine $(16.8 \mathrm{~g} / \mathrm{kg}$ DM) and methionine (4.8 $\mathrm{g} / \mathrm{kg} \mathrm{DM})$ in CM2 and TM2 milks resulted in similar levels of total intake of lysine and methionine for the four milks. Tallow $(181 \mathrm{~g} / \mathrm{kg} \mathrm{DM})$ and coconut oil $(90 \mathrm{~g} / \mathrm{kg} \mathrm{DM})$ were introduced in the control milks, CM2 and $\mathrm{CH} 2$, whilst tricaproin $(113 \mathrm{~g} / \mathrm{kg} \mathrm{DM})$, substituted for an isoenergetic amount of tallow, was interesterified with tallow before spray-drying milks TM2 and TH2.

\section{Lambs and their management}

All lambs were removed from the ewes within a few hours after sucking colostrum.

Trial 1 (one replication) involved sixteen preruminant male lambs of the Limousin breed born in spring (April) and separated at the age of 5 or $6 \mathrm{~d}$ into four homologous groups on the basis of birth weight, and used for $\mathrm{N}$ balance studies at the ages of 2 weeks (four lambs per group) and 5 weeks (three lambs per group).

Trial 2 (two replications) involved twenty-four preruminant male lambs of the Limousin breed. Half of the lambs were born in autumn (November) and half in spring (April). They were separated into four homologous groups and housed in metabolism crates immediately after being removed from the ewes. They were used for three consecutive 1 - week $\mathrm{N}$ balance 
Table 1. Composition ( $\mathrm{g} / \mathrm{kg}$ dry matter) of milk substitutes

\begin{tabular}{|c|c|c|c|c|c|c|c|c|}
\hline \multirow{2}{*}{$\begin{array}{l}\text { Trial... } \\
\text { Diet... }\end{array}$} & \multicolumn{4}{|c|}{1} & \multicolumn{4}{|c|}{2 and 3} \\
\hline & $\mathrm{CMI}$ & $\mathrm{CH} 1$ & TM1 & THI & $\mathrm{CM} 2$ & $\mathrm{CH} 2$ & TM2 & TH2 \\
\hline Skim-milk powder & 400 & 615 & 400 & 604 & $565 \cdot 3$ & $570 \cdot 9$ & $565 \cdot 3$ & $514 \cdot 6$ \\
\hline Methionine & - & - & - & - & 4.8 & $2 \cdot 2$ & 4.8 & $2 \cdot 2$ \\
\hline Lysine & - & - & - & - & 16.8 & $6 \cdot 1$ & 16.8 & $6 \cdot 1$ \\
\hline Fish protein & 90 & 100 & 90 & 102 & - & - & - & - \\
\hline Whey protein & - & - & - & - & - & $144 \cdot 8$ & - & $173 \cdot 6$ \\
\hline Whey powder & 225 & - & 216 & - & - & - & - & - \\
\hline Lactose & - & - & - & - & 137.1 & - & $109 \cdot 6$ & - \\
\hline Tallow & 160 & 160 & 96 & 96 & $161 \cdot 0$ & $161 \cdot 0$ & 87.5 & $87 \cdot 5$ \\
\hline Coconut oil & 90 & 90 & 72 & 72 & $80 \cdot 4$ & $80 \cdot 4$ & $80 \cdot 4$ & $80 \cdot 4$ \\
\hline Tricaproin & - & - & 90 & 90 & - & - & $101 \cdot 0$ & $101 \cdot 0$ \\
\hline Emulsifier* & 10 & 10 & 11 & 11 & $14 \cdot 6$ & $14 \cdot 6$ & $14 \cdot 6$ & $14 \cdot 6$ \\
\hline $\begin{array}{l}\text { Lactic ferment and } \\
\text { mineral and vita- } \\
\text { min supplements } \dagger\end{array}$ & 25 & 25 & 25 & 25 & $20 \cdot 0$ & 20.0 & $20 \cdot 0$ & $20 \cdot 0$ \\
\hline
\end{tabular}

* Lecithin was used in trial 1 and sucroglycerides were used in trials 2 and 3.

$+4 \mathrm{~g} \mathrm{MgCl}_{2} .6 \mathrm{H}_{2} \mathrm{O} ; 50 \mathrm{mg} \mathrm{FeSO}{ }_{4} .7 \mathrm{H}_{2} \mathrm{O} ; 50 \mathrm{mg} \mathrm{ZnO} ; 50 \mathrm{mg} \mathrm{MnSO}{ }_{4} .4 \mathrm{H}_{2} \mathrm{O} ; 20 \mathrm{mg} \mathrm{CuSO} \mathrm{C}_{4} .5 \mathrm{H}_{2} \mathrm{O} ; 8 \mathrm{mg} \mathrm{KI}$; $0.6 \mathrm{mg} \mathrm{CoCl}, 3.6 \mathrm{mg}$ vitamin $\mathrm{A} ; 240 \mathrm{mg}$ vitamin $\mathrm{D} ; 50 \mathrm{mg}$ vitamin $\mathrm{E} ; 2 \mathrm{mg}$ vitamin $\mathrm{K} ; 2 \mathrm{mg}$ vitamin $\mathrm{B}_{1} ; 4 \mathrm{mg}$ vitamin $\mathrm{B}_{2} ; 2 \mathrm{mg}$ vitamin $\mathrm{B}_{6} ; 0.05 \mathrm{mg}$ vitamin $\mathrm{B}_{12} ; 0.75 \mathrm{mg}$ biotin; $2 \mathrm{mg}$ calcium pantothenate; $1.8 \mathrm{~g}$ choline; $50 \mathrm{mg}$ furazolidone.

Table 2. Main features of milk constituents $(\mathrm{g} / \mathrm{kg}$ dry matter $(D M))$ and experimental design

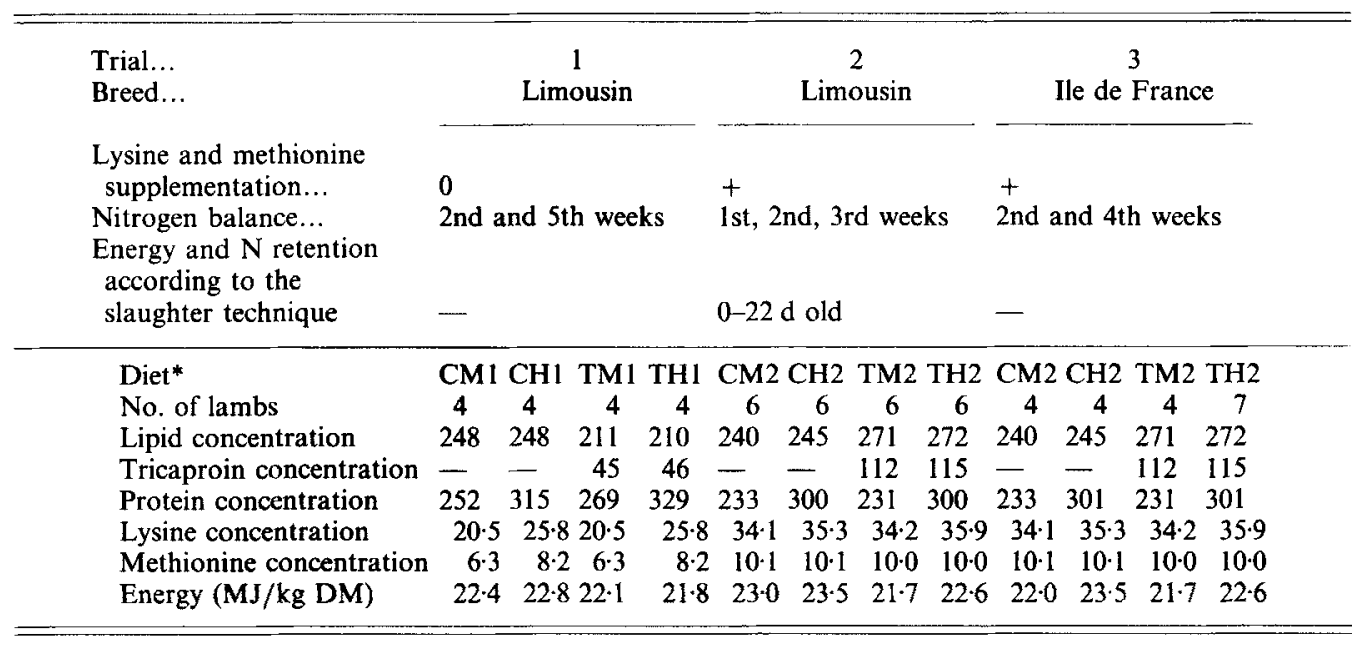

* For details see p. 526.

determinations, and to study energy and protein retention during the first 3 weeks after birth by the comparative slaughter technique.

Trial 3 involved nineteen preruminant male lambs of the Ile de France breed separated into three groups of four lambs and one group of seven lambs (four + three) which were used for N-balance studies at the ages of 2 and 4 weeks. Because of low prolificacy there 
were not enough lambs for the second replication, in spring, and only the first replication, in autumn, was fully completed.

\section{Experimental features and analysis}

The milk substitutes, reconstituted at a rate of $160 \mathrm{~g} / 1$, were offered $a d$ lib., fresh milk being prepared twice daily. Amounts offered and refused were weighed individually and portions were taken for analysis. Faeces were collected in beakers attached to the lambs by harnesses (Tissier et al. 1975). Urine was collected in flasks (containing $100 \mathrm{ml} 6 \mathrm{M}$-hydrochloric acid to prevent any ammonia loss) in trial 1 with the help of gutter-shaped plastic sheets under the wire-floor of the crates, or in trials 2 and 3 with the help of rigid plastic funnels. Crate floors and plastic sheets or funnels were washed daily and representative samples of urine and water used for washing were taken for analysis.

The lambs were slaughtered at a mean age of $22 \mathrm{~d}$. At slaughter, the body of the lamb was separated into skin, wool, blood, viscera, head, feet and carcass. The carcasses were further dissected into muscles, bones and adipose tissues. Each compartment was immediately weighed, frozen and kept at $-15^{\circ}$. The different compartments were ground in the frozen state in liquid $\mathrm{N}_{2}$ using a Stephan screw homogenizer and the analysis of moisture, energy and $\mathrm{N}$ performed on the powder obtained. Body composition of the lambs at the start of the trial was assessed from the analysis of the bodies of fourteen new-born lambs of the same breed (Villette \& Aurousseau, 1981).

The detailed description of the handling and analysis of the samples have been given in Vermorel et al. (1973). Energy and $\mathrm{N}$ concentrations in the samples were determined on the DM using a Gallenkamp adiabatic calorimeter and by the Kjeldahl method, respectively.

The relations between metabolizable energy (ME) intake, age of the lambs (A) and protein concentration in the milk $(P)$ were investigated using the AMANCE 81 statistical programs (Bachacou et al. 1981). Different combinations of the three variables were tested by stepwise forward regression. On the basis of the best regression obtained, the different values of $\mathbf{N}$ balance were adjusted to the same mean $\mathrm{ME} ; \mathrm{A}$ and $\mathbf{P}$ were compared according to the Student's $t$ test (Snedecor \& Cochran, 1956).

\section{RESULTS}

\section{Effects of tricaproin inclusion and milk protein concentration on $N$ balance}

The most striking feature of the trials was the wide individual variation in live weight and level of ME intake, and consequently in growth rate (Tables 3-5). Moreover, energy and $\mathbf{N}$ digestibilities showed similarly wide individual variations as well as age-related changes (Aurousseau et al. 1983a). Thus it was not possible to obtain a reliable relation between $\mathrm{ME}$ intake and tissue $\mathrm{N}$ deposition for a given diet offered to a group of lambs of a particular age. A multiple regression was therefore used for the whole set of data, relating daily tissue $\mathrm{N}$ deposition ( $\mathrm{NF} ; \mathrm{g} / \mathrm{kg}$ body-weight ${ }^{0 \cdot 75}$ ) to daily $\mathrm{ME}$ intake ( $\mathrm{MJ} / \mathrm{kg}$ bodyweight ${ }^{0.75}$ ), age of the lambs $(\mathrm{A}, \mathrm{d})$ and protein concentration in the milk ( $\left.\mathrm{P}, \mathrm{g} / \mathrm{g} \mathrm{DM}\right)$. There were no significant differences in the $\mathrm{N}$ balances of lambs born in autumn and those born in spring (trial 2). Quadratic and cubic effects of ME or age were first tested, but a quadratic effect of $\mathbf{P}$ was introduced to improve the fit of the relation to the data.

A single equation could thus be calculated for each milk ( $\mathrm{C}$ or $\mathrm{T})$ prepared with a similar type of fat (i.e. tallow-coconut oil or tallow-coconut oil-tricaproin) taking into account values obtained from the 1 st to the 5 th week for the two concentrations of crude protein $(\mathrm{N} \times 6.25), \mathrm{M}$ or $\mathrm{H}$. 
Table 3. Trial 1. Effects of inclusion of tricaproin and protein concentration in milk on nitrogen balance in Limousin preruminant male lambs

(Mean values and standard deviations)

\begin{tabular}{|c|c|c|c|c|c|c|c|c|}
\hline \multirow[t]{2}{*}{ Diet... } & \multicolumn{2}{|c|}{ CM1 } & \multicolumn{2}{|c|}{$\mathrm{CHI}$} & \multicolumn{2}{|c|}{ TM1 } & \multicolumn{2}{|c|}{ TH1 } \\
\hline & Mean & SD & Mean & $\overline{\text { SD }}$ & Mean & SD & Mean & $\mathrm{SD}$ \\
\hline Age (d) & 10.8 & 0.2 & $10 \cdot 5$ & $1 \cdot 3$ & $10 \cdot 8$ & 1.7 & $10 \cdot 8$ & $1 \cdot 3$ \\
\hline Live-wt (kg) & 5.6 & 0.5 & $6 \cdot 2$ & $1 \cdot 0$ & 5.9 & 0.6 & $5 \cdot 8$ & 0.9 \\
\hline Daily wt gain $(\mathrm{g} / \mathrm{d})$ & 224 & 39 & 269 & 56 & 242 & 47 & 272 & 78 \\
\hline $\mathrm{ME}(\mathrm{MJ} / \mathrm{d})$ & $4 \cdot 32$ & 0.60 & $4 \cdot 58$ & 0.61 & $4 \cdot 83$ & 0.24 & $4 \cdot 37$ & 0.65 \\
\hline Lysine $(\mathrm{g} / \mathrm{d})$ & $4 \cdot 25$ & 0.57 & $5 \cdot 66$ & 0.76 & 4.69 & 0.25 & $5 \cdot 57$ & $1 \cdot 13$ \\
\hline Methionine (g/d) & $1 \cdot 31$ & $0 \cdot 17$ & 1.79 & $0 \cdot 24$ & $1 \cdot 44$ & 0.07 & $1 \cdot 77$ & 0.36 \\
\hline Digestible $N(g / d)$ & 8.04 & 1.07 & $10 \cdot 63$ & 1.43 & $9 \cdot 66$ & 0.51 & $11 \cdot 14$ & 2.65 \\
\hline $\mathrm{N}$ balance $(\mathrm{g} / \mathrm{d})$ & 5.68 & 0.77 & $6 \cdot 17$ & $1 \cdot 19$ & 6.76 & 0.79 & 7.01 & 1.69 \\
\hline Adjusted $\mathrm{N}$ balance $(\mathrm{g} / \mathrm{d})^{*}$ & $601^{a}$ & $0 \cdot 11$ & $6 \cdot 21^{\mathrm{b}}$ & 0.11 & $6.27^{\mathrm{b}}$ & $0 \cdot 10$ & $7 \cdot 11^{c}$ & $0 \cdot 10$ \\
\hline Age (d) & $31 \cdot 3$ & $0 \cdot 6$ & $32 \cdot 0$ & $1 \cdot 0$ & $31 \cdot 7$ & $2 \cdot 1$ & $32 \cdot 3$ & $1 \cdot 4$ \\
\hline Live-wt (kg) & $10 \cdot 4$ & 0.5 & $11 \cdot 1$ & 0.8 & $10 \cdot 4$ & $1 \cdot 2$ & 11.9 & $1 \cdot 1$ \\
\hline Daily wt gain $(g / d)$ & 239 & 90 & 241 & 49 & 279 & 63 & 283 & 21 \\
\hline $\mathrm{ME}(\mathrm{MJ} / \mathrm{d})$ & 6.90 & 0.65 & 6.91 & $1 \cdot 23$ & 6.27 & 4.09 & $7 \cdot 47$ & $0 \cdot 19$ \\
\hline Lysine $(g / d)$ & 6.72 & 0.63 & 8.40 & $1 \cdot 51$ & $6 \cdot 11$ & $3 \cdot 35$ & $9 \cdot 54$ & $0 \cdot 26$ \\
\hline Methionine $(\mathrm{g} / \mathrm{d})$ & $2 \cdot 12$ & $0 \cdot 20$ & $2 \cdot 56$ & 0.46 & 1.88 & 1.03 & 3.03 & 0.08 \\
\hline Digestible $N(g / d)$ & $12 \cdot 77$ & $1 \cdot 19$ & $16 \cdot 05$ & $2 \cdot 89$ & 12.65 & $8 \cdot 2$ & $19 \cdot 20$ & 0.53 \\
\hline $\mathrm{N}$ balance $(\mathrm{g} / \mathrm{d})$ & 7.78 & 1.41 & $7 \cdot 81$ & 0.95 & 7.91 & $6 \cdot 12$ & $9 \cdot 46$ & 0.38 \\
\hline Adjusted $\mathrm{N}$ balance $(\mathrm{g} / \mathrm{d}) \dagger$ & $7 \cdot 88^{\mathrm{a}}$ & $0 \cdot 17$ & $7 \cdot 48^{b}$ & 0.19 & $8 \cdot 30^{c}$ & $0 \cdot 17$ & $8 \cdot 87^{\mathrm{d}}$ & $0 \cdot 16$ \\
\hline
\end{tabular}

ME, metabolizable energy; CM 1, tallow-coconut oil, $240 \mathrm{~g}$ protein $/ \mathrm{kg}$ dry matter (DM); CH l, tallow-coconut oil, $320 \mathrm{~g}$ protein $/ \mathrm{kg}$ DM; TM 1 , tallow-coconut oil-tricaproin, $240 \mathrm{~g}$ protein $/ \mathrm{kg} \mathrm{DM;} \mathrm{TH1,} \mathrm{tallow-coconut}$ oil-tricaproin, $320 \mathrm{~g}$ protein $/ \mathrm{kg} \mathrm{DM}$.

a.b.e.a Values with different superscript letters differed significantly $(P<0.05)$

* Values adjusted for a mean body-weight of $5.9 \mathrm{~kg}$, a mean age of $17.0 \mathrm{~d}$, a mean $\mathrm{ME}$ intake of $4.53 \mathrm{MJ} / \mathrm{d}$ and a mean digestible $\mathrm{N}$ intake of $8.72 \mathrm{~g} / \mathrm{d}$ for diets $\mathrm{M}$ or $11.01 \mathrm{~g} / \mathrm{d}$ for diets $\mathrm{H}$.

$\dagger$ Values adjusted for a mean body-weight of $11.0 \mathrm{~kg}$, a mean age of $31.8 \mathrm{~d}$, a mean $\mathrm{ME}$ intake of $6.88 \mathrm{MJ} / \mathrm{d}$ and a mean digestible $N$ intake of $13.31 \mathrm{~g} / \mathrm{d}$ for diets $M$ or $16.83 \mathrm{~g} / \mathrm{d}$ for diets $\mathrm{H}$.

Trial 1. Unsupplemented milks offered to Limousin lambs. The following relations were obtained for milks CM1 and CH1:

$$
\begin{array}{clc}
\mathrm{NF}=11.0 \times \mathrm{ME} \times \mathrm{P}-16.2 \times \mathrm{ME} \times \mathrm{P}^{2}-0.114 \times \mathrm{ME} \times \mathrm{A} \times \mathrm{P}^{2}-0.443 \\
(\text { SD 2.0) } & (\text { SD } 4.2) & (\text { SD } 0.028) \\
& \text { Residual SD } 0.107 ; r^{2} 0.87,
\end{array}
$$

or for milks TM1 and TM2:

$$
\begin{aligned}
& \mathrm{NF}=8.7 \times \mathrm{ME} \times \mathrm{P}-8.31 \times \mathrm{ME} \times \mathrm{P}^{2}-0.126 \times \mathrm{ME} \times \mathrm{A} \times \mathrm{P}^{2}-0.264 \\
& \begin{array}{llll}
(\text { SD } 0.9) \quad(\text { SD 2.67) } \quad(\text { SD } 0.023) & \text { (SD 0.156) }
\end{array} \\
& \text { Residual SD } 0 \cdot 101 ; r^{2} 0.97 \text {. }
\end{aligned}
$$

The partial regression coefficients of both equations were significant $(P<0.05)$ but the $y$ intercepts were not. Means adjusted for similar weights, A, ME and digestible protein intakes, were calculated for each of the four groups of lambs and for the two periods when $\mathrm{N}$ balances were determined (Table 3). In 2-week-old lambs, tissue $\mathbf{N}$ deposition (NF) was significantly higher $(P<0.05)$ for the milk containing tricaproin $(+4.3 \%$ in group TM1 compared with group $\mathrm{CM} 1$, or $+14.5 \%$ in group $\mathrm{TH} 1$ compared with group $\mathrm{CH} 1$ ) and 
Table 4. Trial 2. Effects of inclusion of tricaproin and protein concentration in milk on nitrogen balance in Limousin preruminant male lambs given milks supplemented with lysine and methionine

(Mean values and standard deviations)

\begin{tabular}{|c|c|c|c|c|c|c|c|c|}
\hline \multirow[t]{2}{*}{ Diet... } & \multicolumn{2}{|c|}{$\mathrm{CM} 2$} & \multicolumn{2}{|c|}{$\mathrm{CH} 2$} & \multicolumn{2}{|c|}{ TM2 } & \multicolumn{2}{|c|}{ TH2 } \\
\hline & Mean & SD & Mean & SD & Mean & SD & Mean & $\overline{\text { SD }}$ \\
\hline Age (d) & 5.0 & $1 \cdot 1$ & $5 \cdot 0$ & $1 \cdot 1$ & $5 \cdot 0$ & 0.9 & $5 \cdot 7$ & 1.2 \\
\hline Live wt $(\mathrm{kg})$ & $4 \cdot 1$ & 0.5 & $4 \cdot 3$ & 0.4 & 3.8 & 0.6 & $4 \cdot 0$ & 0.6 \\
\hline Daily wt gain $(\mathrm{g} / \mathrm{d})$ & 209 & 32 & 233 & 42 & 180 & 113 & 272 & 50 \\
\hline $\mathrm{ME}(\mathrm{MJ} / \mathrm{d})$ & 3.59 & 0.98 & 3.41 & 0.63 & 2.87 & $1 \cdot 13$ & $3 \cdot 74$ & 0.65 \\
\hline Lysine $(\mathrm{g} / \mathrm{d})$ & $6 \cdot 37$ & 1.63 & 5.76 & 1.01 & 4.91 & 1.78 & $6 \cdot 42$ & $1 \cdot 14$ \\
\hline Methionine $(\mathrm{g} / \mathrm{d})$ & 1.89 & $0 \cdot 48$ & 1.65 & 0.29 & 1.44 & 0.52 & 1.79 & 0.32 \\
\hline Digestible $N(\mathrm{~g} / \mathrm{d})$ & 6.58 & 1.68 & $7 \cdot 48$ & $1 \cdot 31$ & $5 \cdot 21$ & 1.89 & $8 \cdot 43$ & 1.50 \\
\hline $\mathrm{N}$ balance $(\mathrm{g} / \mathrm{d})$ & $5 \cdot 48$ & $1 \cdot 41$ & $5 \cdot 01$ & $1 \cdot 24$ & $4 \cdot 21$ & 2.06 & 6.57 & 1.53 \\
\hline Adjusted $\mathrm{N}$ balance $(\mathrm{g} / \mathrm{d})^{*}$ & $4.82^{a}$ & 0.06 & $4.93^{\mathrm{a}}$ & 0.06 & $5 \cdot 23^{\mathrm{c}}$ & 0.08 & $5 \cdot 55^{\mathrm{d}^{\circ}}$ & 0.09 \\
\hline Age (d) & $12 \cdot 3$ & 1.4 & $11 \cdot 2$ & $1 \cdot 0$ & $12 \cdot 2$ & 0.8 & $12 \cdot 0$ & $1 \cdot 1$ \\
\hline Live wt (g/d) & $5 \cdot 5$ & 0.5 & 5.6 & 0.4 & $5 \cdot 1$ & 0.8 & $5 \cdot 6$ & 0.8 \\
\hline Daily wt gain $(\mathrm{g} / \mathrm{d})$ & 199 & 38 & 212 & 25 & 221 & 25 & 265 & 51 \\
\hline $\mathrm{ME}(\mathrm{MJ} / \mathrm{d})$ & $4 \cdot 81$ & 0.38 & 4.98 & 0.62 & $4 \cdot 44$ & 0.77 & $5 \cdot 14$ & 0.68 \\
\hline Lysine $(g / d)$ & 7.93 & 0.69 & 7.97 & 0.95 & $7 \cdot 31$ & $1 \cdot 21$ & $8 \cdot 66$ & 1.05 \\
\hline Methionine $(\mathrm{g} / \mathrm{d})$ & $2 \cdot 35$ & 0.20 & $2 \cdot 28$ & 0.27 & $2 \cdot 14$ & 0.35 & $2 \cdot 41$ & 0.29 \\
\hline Digestible $N(\mathrm{~g} / \mathrm{d})$ & $8 \cdot 45$ & 0.73 & $10 \cdot 64$ & $1 \cdot 27$ & 7.76 & $1 \cdot 28$ & $11 \cdot 37$ & 1.38 \\
\hline $\mathrm{N}$ balance $(\mathrm{g} / \mathrm{d})$ & $6 \cdot 21$ & 0.83 & $6 \cdot 39$ & 1.03 & $6 \cdot 42$ & $1 \cdot 19$ & $7 \cdot 38$ & $1 \cdot 19$ \\
\hline Adjusted $\mathrm{N}$ balance $(\mathrm{g} / \mathrm{d}) \dagger$ & $6 \cdot 34^{a}$ & 0.07 & $6 \cdot 32^{\mathrm{a}}$ & 0.08 & $6 \cdot 89^{\mathrm{b}}$ & $0 \cdot 10$ & $7 \cdot 17^{\mathrm{b}}$ & 0.11 \\
\hline Age (d) & $19 \cdot 8$ & $1 \cdot 2$ & $19 \cdot 0$ & 1.3 & $19 \cdot 5$ & $2 \cdot 3$ & $19 \cdot 7$ & 1.5 \\
\hline Live wt (g/d) & 6.9 & $0 \cdot 8$ & $7 \cdot 7$ & $1 \cdot 2$ & 6.9 & 0.9 & $7 \cdot 5$ & $1 \cdot 1$ \\
\hline Daily wt gain $(g / d)$ & 199 & 43 & 227 & 60 & 221 & 61 & 217 & 64 \\
\hline $\mathrm{ME}(\mathrm{MJ} / \mathrm{d})$ & 5.43 & $0 \cdot 72$ & $6 \cdot 23$ & 0.67 & 5.72 & $0 \cdot 81$ & 6.04 & 1.02 \\
\hline Lysine $(\mathrm{g} / \mathrm{d})$ & $8 \cdot 54$ & 0.84 & $9 \cdot 90$ & 1.03 & $9 \cdot 28$ & 1.09 & $10 \cdot 18$ & 1.71 \\
\hline Methionine (g/d) & $2 \cdot 53$ & $0 \cdot 25$ & 2.83 & $0 \cdot 30$ & 2.71 & 0.32 & $2 \cdot 84$ & 0.48 \\
\hline Digestible N (g/d) & $9 \cdot 17$ & 0.90 & $13 \cdot 22$ & $1 \cdot 38$ & $9 \cdot 85$ & $1 \cdot 16$ & $13 \cdot 37$ & $2 \cdot 24$ \\
\hline $\mathrm{N}$ balance $(\mathrm{g} / \mathrm{d})$ & $5 \cdot 89$ & 0.87 & $7 \cdot 23$ & $1 \cdot 29$ & $7 \cdot 10$ & 0.78 & $7 \cdot 17$ & $1 \cdot 10$ \\
\hline Adjusted $\mathrm{N}$ balance $(\mathrm{g} / \mathrm{d}) \ddagger$ & $6.71^{\mathrm{b}}$ & $0 \cdot 09$ & $6 \cdot 21^{\mathrm{a}}$ & 0.09 & $7 \cdot 29^{\mathrm{c}}$ & $0 \cdot 13$ & $7 \cdot 10^{\mathrm{e}}$ & 0.13 \\
\hline
\end{tabular}

ME, metabolizable energy; CM2, tallow-coconut oil, $230 \mathrm{~g}$ protein/kg dry matter (DM); $\mathrm{CH} 2$, tallow-coconut oil, $300 \mathrm{~g}$ protein $/ \mathrm{kg} \mathrm{DM}$; TM2, tallow-coconut oil-tricaproin, $230 \mathrm{~g}$ protein $/ \mathrm{kg} \mathrm{DM}$; $\mathrm{TH} 2$, tallow-coconut oiltricaproin, $300 \mathrm{~g}$ protein $/ \mathrm{kg} \mathrm{DM}$.

$a, 3, e, \AA$ Values with different superscript letters differed significantly $(P<0.05)$

* Values adjusted for a mean body-weight of $4.0 \mathrm{~kg}$, a mean age of $6.3 \mathrm{~d}$, a mean ME intake of $3.40 \mathrm{MJ} / \mathrm{d}$ and a mean digestible $\mathrm{N}$ intake of $6.26 \mathrm{~g} / \mathrm{d}$ for diets $\mathrm{M}$ or $7.56 \mathrm{~g} / \mathrm{d}$ for diets $\mathrm{H}$

$\dagger$ Values adjusted for a mean body-weight of $5.5 \mathrm{~kg}$, a mean age of $11.5 \mathrm{~d}$, a mean intake of $4.84 \mathrm{MJ} / \mathrm{d}$ and a mean digestible $\mathrm{N}$ intake of $8.51 \mathrm{~g} / \mathrm{d}$ for diets $\mathrm{M}$ or $10.53 \mathrm{~g} / \mathrm{d}$ for diets $\mathrm{H}$.

\# Values adjusted for a mean body-weight of $7 \cdot 2 \mathrm{~kg}$, a mean age of $19 \cdot 1 \mathrm{~d}$, a mean ME intake of $5.84 \mathrm{MJ} / \mathrm{d}$ and a mean digestible $\mathrm{N}$ intake of $10.32 \mathrm{~g} / \mathrm{d}$ for diets $\mathrm{M}$ or $12.68 \mathrm{~g} / \mathrm{d}$ for diets $\mathrm{H}$.

also higher after a $26 \%$ increase in protein concentration in the milks $(+3 \cdot 3 \%$ in group $\mathrm{CH} 1$ compared with group CM1, or $+13.4 \%$ in group TH1 compared with group TM1). In 5-week-old lambs, NF was significantly higher $(P<0.05)$ for the milk containing tricaproin $(+5 \cdot 3 \%$ in group TM1 compared with group CM1, or $+18.6 \%$ in group TH1 compared with group $\mathrm{CH} 1)$ but the increase in protein concentration led to adverse results: there was a significant $(P<0.05)$ decrease in NF for the control milks $(-5.1 \%$ in group CH1 compared with group CM1) but a significant $(P<0.05)$ increase for the milks containing tricaproin $(+6.9 \%$ in group TH1 compared with group TM1). 
Table 5. Trial 3. Effects of inclusion of tricaproin and protein concentration in milk on nitrogen balance in Ile de France preruminant male lambs given milks supplemented with lysine and methionine

(Mean values and standard deviations)

\begin{tabular}{|c|c|c|c|c|c|c|c|c|}
\hline \multirow[t]{2}{*}{ Diet... } & \multicolumn{2}{|c|}{$\mathrm{CM} 2$} & \multicolumn{2}{|c|}{$\mathrm{CH} 2$} & \multicolumn{2}{|c|}{$\mathrm{TM} 2$} & \multicolumn{2}{|c|}{$\mathrm{TH} 2$} \\
\hline & Mean & SD & Mean & SD & Mean & SD & Mean & SD \\
\hline Age (d) & $9 \cdot 3$ & 0.5 & 9.0 & & $10 \cdot 0$ & & $10 \cdot 7$ & $2 \cdot 2$ \\
\hline Live wt $(\mathrm{kg})$ & $5 \cdot 2$ & 0.8 & $6 \cdot 2$ & 0.8 & $5 \cdot 2$ & 0.4 & $6 \cdot 2$ & $1-0$ \\
\hline Daily wt gain $(g / d)$ & 237 & 34 & 332 & 23 & 241 & 30 & 264 & 63 \\
\hline $\mathrm{ME}(\mathrm{MJ} / \mathrm{d})$ & $4 \cdot 6$ & $0 \cdot 9$ & 6.0 & 0.7 & $4 \cdot 6$ & $0 \cdot 4$ & $5 \cdot 4$ & $1 \cdot 3$ \\
\hline Lysine (g/d) & $8 \cdot 15$ & $1 \cdot 46$ & $10 \cdot 90$ & $1 \cdot 21$ & 8.04 & 0.63 & $9 \cdot 24$ & $2 \cdot 40$ \\
\hline Methionine $(\mathrm{g} / \mathrm{d})$ & $2 \cdot 41$ & 0.43 & $3 \cdot 12$ & 0.35 & $2 \cdot 35$ & $0 \cdot 18$ & 2.57 & 0.67 \\
\hline Digestible $N(g / d)$ & $8 \cdot 42$ & $1 \cdot 51$ & $14 \cdot 44$ & $1 \cdot 60$ & $8 \cdot 33$ & 0.65 & $11 \cdot 84$ & $3 \cdot 08$ \\
\hline $\mathrm{N}$ balance $(\mathrm{g} / \mathrm{d})$ & 6.96 & $1-51$ & 9.93 & 1.35 & 6.58 & 0.98 & $8-46$ & $2 \cdot 72$ \\
\hline Adjusted $\mathrm{N}$ balance $(\mathrm{g} / \mathrm{d})^{*}$ & $7 \cdot 72^{\mathrm{a}}$ & $0 \cdot 12$ & $8 \cdot 41^{b}$ & $0 \cdot 12$ & $7 \cdot 63^{a}$ & 0.13 & $8 \cdot 38^{\mathrm{b}}$ & 0.13 \\
\hline Age (d) & $19 \cdot 7$ & 0.5 & $18 \cdot 5$ & 1.0 & $19 \cdot 0$ & - & $18 \cdot 9$ & $1 \cdot 5$ \\
\hline Live wt (kg) & $7 \cdot 7$ & 0.8 & 8.9 & $1 \cdot 0$ & $8 \cdot 3$ & 0.7 & 8.5 & 0.9 \\
\hline Daily wt gain $(g / d)$ & 248 & 39 & 267 & 28 & 280 & 61 & 250 & 63 \\
\hline $\mathrm{ME}(\mathrm{MJ} / \mathrm{d})$ & $6 \cdot 4$ & $0 \cdot 4$ & $6 \cdot 8$ & 0.4 & $6 \cdot 9$ & $0 \cdot 5$ & $6 \cdot 4$ & $1 \cdot 3$ \\
\hline Lysine (g/d) & $10 \cdot 86$ & 0.72 & 11.93 & 0.75 & $11 \cdot 27$ & 0.76 & $10 \cdot 57$ & $2 \cdot 34$ \\
\hline Methionine $(\mathrm{g} / \mathrm{d})$ & $3 \cdot 22$ & $0 \cdot 21$ & $3 \cdot 41$ & $0 \cdot 21$ & $3 \cdot 30$ & 0.22 & $2 \cdot 94$ & 0.65 \\
\hline Digestible $N(g / d)$ & 11.42 & 0.76 & $15 \cdot 72$ & 0.99 & 11.83 & $0 \cdot 80$ & 13.67 & 3.02 \\
\hline $\mathrm{N}$ balance $(\mathrm{g} / \mathrm{d})$ & $7 \cdot 78$ & 0.85 & $8 \cdot 76$ & 0.83 & $8 \cdot 64$ & 0.59 & 7.99 & 1.81 \\
\hline Adjusted $\mathrm{N}$ balance $(\mathrm{g} / \mathrm{d}) \dagger$ & $8 \cdot 18$ & $0 \cdot 15$ & $8 \cdot 33$ & $0 \cdot 14$ & 8.03 & 0.13 & $8 \cdot 30$ & $0 \cdot 16$ \\
\hline
\end{tabular}

ME, metabolizable energy; CM2, tallow-coconut oil, $230 \mathrm{~g}$ protein/kg dry matter (DM); CH2, tallow-coconut oil, $300 \mathrm{~g}$ protein $/ \mathrm{kg}$ DM; TM2, tallow-coconut oil-tricaproin, $230 \mathrm{~g}$ protein $/ \mathrm{kg} \mathrm{DM}$; TH2, tallow-coconut oil tricaproin, $300 \mathrm{~g}$ protein $/ \mathrm{kg}$ DM.

a. $b$ Values with different superscript letters differed significantly $(P<0.001)$.

* Values adjusted for a mean body-weight of $5.8 \mathrm{~kg}$, a mean age of $9 \cdot 6 \mathrm{~d}$, a mean ME intake of $5 \cdot 19 \mathrm{MJ} / \mathrm{d}$ and a mean digestible $\mathrm{N}$ intake of $9.44 \mathrm{~g} / \mathrm{d}$ for diets $\mathrm{M}$ or $11.81 \mathrm{~g} / \mathrm{d}$ for diets $\mathrm{H}$.

$\dagger$ Values adjusted for a mean body-weight of $8.4 \mathrm{~kg}$, a mean age of $19.0 \mathrm{~d}$, a mean ME intake of $6.58 \mathrm{MJ} / \mathrm{d}$ and a mean digestible $\mathrm{N}$ intake of $11.53 \mathrm{~g} / \mathrm{d}$ for diets $\mathrm{M}$ or $14.49 \mathrm{~g} / \mathrm{d}$ for diets $H$.

Trial 2. Lysine- and methionine-supplemented diets offered to Limousin lambs. The following relations were obtained for milks $\mathrm{CM} 2$ and $\mathrm{CH} 2$ :

$$
\begin{array}{ccc}
\mathrm{NF}=11.4 \times \mathrm{ME} \times \mathrm{P}-17.3 \times \mathrm{ME} \times \mathrm{P}^{2}-0.354 \times \mathrm{ME} \times \mathrm{A} \times \mathrm{P}^{2}-0.231 \\
(\mathrm{SD} 1 \cdot 1) & (\mathrm{SD} 2.5) & (\text { SD } 0.0394) \\
& \text { Residual SD 0.126; } r^{2} 0.85
\end{array}
$$

or for milks TM2 and TH2:

$$
\begin{array}{cccc}
\mathrm{NF}=12.4 \times \mathrm{ME} & \mathrm{P}-17.0 \times \mathrm{ME} \times \mathrm{P}^{2}-0.410 \times \mathrm{ME} \times \mathrm{A} \times \mathrm{P}^{2}-0.352 \\
(\mathrm{SD} \mathrm{1.3)} & (\mathrm{SD} 3.3) & (\mathrm{SD} 0.049) & (\text { SD 0.238) } \\
& \text { Residual SD 0.164; } r^{2} 0.88 .
\end{array}
$$

In 1-week-old lambs, adjusted mean $\mathrm{N}$ balances (Table 4$)$ were significantly higher $(P<$ $0.05)$ when tricaproin was introduced in the milk $(+8.5 \%$ in group TM2 compared with group $\mathrm{CM} 2$, or $+12.6 \%$ in group $\mathrm{TH} 2$ compared with group $\mathrm{CH} 2$ ) and also after an increase in protein concentration $(+2.3 \%$, not significant, in group $\mathrm{CH} 2$ compared with group CM2, or $+6.1 \%, P<0.05$, in group TH2 compared with group TM2).

At 2 and 3 weeks of age, $\mathrm{N}$ balances were still significantly higher with tricaproin 
Table 6. Trial 2. Effects of inclusion of tricaproin and of protein concentration in milk on protein and lipid deposition in preruminant male Limousin lambs between birth and 3 weeks of age

(Mean values and standard deviations)

\begin{tabular}{|c|c|c|c|c|c|c|c|c|}
\hline \multirow[t]{2}{*}{ Diet... } & \multicolumn{2}{|c|}{$\mathrm{CM} 2$} & \multicolumn{2}{|c|}{$\mathrm{TM} 2$} & \multicolumn{2}{|c|}{$\mathrm{CH} 2$} & \multicolumn{2}{|c|}{ TH2 } \\
\hline & Mean & SD & Mean & SD & Mean & SD & Mean & SD \\
\hline No. of lambs & 6 & - & 6 & - & 6 & - & 6 & \\
\hline Initial wt $(\mathrm{kg})$ & $3 \cdot 3$ & $0 \cdot 3$ & $3 \cdot 3$ & 0.5 & 3.5 & $0 \cdot 4$ & $3 \cdot 3$ & 0.6 \\
\hline Balance period (d) & $21 \cdot 1$ & $1 \cdot 1$ & $21 \cdot 3$ & $1 \cdot 1$ & $21 \cdot 8$ & 1.7 & $21 \cdot 2$ & $2 \cdot 9$ \\
\hline Final wt $(\mathrm{kg})$ & $7 \cdot 6$ & 0.8 & $7 \cdot 7$ & 0.7 & $8 \cdot 3$ & 0.8 & 8.4 & $1 \cdot 2$ \\
\hline Mean live wt gain $(g / d)$ & 186 & 18 & 185 & 14 & 204 & 24 & 221 & 31 \\
\hline $\mathrm{ME}(\mathrm{MJ} / \mathrm{d})$ & $4 \cdot 762$ & 0.526 & 4.467 & 0.677 & $5 \cdot 103$ & $0 \cdot 328$ & 4.941 & 0.831 \\
\hline Digestible nitrogen $(\mathrm{g} / \mathrm{d})$ & $8 \cdot 268$ & 0.721 & 7.963 & $1 \cdot 180$ & $10 \cdot 694$ & 1.555 & $11 \cdot 218$ & 1.641 \\
\hline Energy deposited (MJ/d) & 1.883 & 0.378 & 1.818 & 0.332 & 2.087 & $0 \cdot 365$ & 2.084 & 0.388 \\
\hline $\begin{array}{l}\text { Adjusted energy deposited } \\
(\mathrm{MJ} / \mathrm{d})^{*}\end{array}$ & 1.881 & $0 \cdot 383$ & 2031 & 0.362 & 1.936 & 0.380 & 2.021 & 0.398 \\
\hline Protein $(\mathrm{g} / \mathrm{d})$ & $39 \cdot 1$ & $6 \cdot 8$ & $41 \cdot 0$ & $4 \cdot 4$ & $41 \cdot 7$ & $3 \cdot 3$ & $46 \cdot 7$ & $4 \cdot 3$ \\
\hline $\begin{array}{l}\text { Protein (\% energy } \\
\text { deposited) }\end{array}$ & $49 \cdot 5$ & $8 \cdot 5$ & $53 \cdot 7$ & $5 \cdot 8$ & $47 \cdot 6$ & $3 \cdot 8$ & 53.4 & 4.9 \\
\hline Lipid $(g / d)$ & $24 \cdot 7$ & $3 \cdot 9$ & 21.9 & $2 \cdot 8$ & $28 \cdot 4$ & $2 \cdot 3$ & $25 \cdot 3$ & $2 \cdot 9$ \\
\hline Lipid (\% energy deposited) & $50 \cdot 5$ & $7 \cdot 9$ & $46 \cdot 3$ & 6.0 & $52 \cdot 4$ & $4 \cdot 2$ & $46 \cdot 6$ & $5 \cdot 4$ \\
\hline
\end{tabular}

ME, metabolizable energy; CM2, tallow-coconut oil, $230 \mathrm{~g}$ protein/kg dry matter (DM); CH2, tallow-coconut oil, $300 \mathrm{~g}$ protein $/ \mathrm{kg}$ DM; TM2, tallow-coconut oil-tricaproin, $230 \mathrm{~g}$ protein $/ \mathrm{kg} \mathrm{DM}$; TH2 tallow-coconut oil-tricaproin, $300 \mathrm{~g}$ protein $/ \mathrm{kg}$ DM.

* Energy deposited, adjusted for similar ME intake $(4.82 \mathrm{MJ} / \mathrm{d})$ and live weight $(5.65 \mathrm{~kg})$.

inclusion $(+8.7 \%$ at both ages in group TM2 compared with group CM2, or $+13.4 \%$ at 2 weeks and $+14.3 \%$ at 3 weeks in group $\mathrm{TH} 2$ compared with group $\mathrm{CH} 2$ ). However, an increase of $24 \%$ in digestible $\mathrm{N}$ intake only slightly altered $\mathrm{N}$ balances with both milks in 2- and 3-week-old lambs. It led to a significant decrease $(-7.5 \%$ in group $\mathrm{CH} 2$ compared with group CM2) for the control milk, and to a similar tendency for the tricaproin milk $(-2 \cdot 2 \%$ in group $\mathrm{TH} 2$ compared with group TM2).

Trial 3. Lysine- and methionine-supplemented milks offered to Ile de France lambs. The following relations were obtained for milks $\mathrm{CM} 2$ and $\mathrm{CH} 2$ :

$$
\begin{array}{ccc}
\mathrm{NF}=9.7 & \mathrm{ME} \times \mathrm{P}-9.32 \times \mathrm{ME} \times \mathrm{P}^{2}-0.468 \times \mathrm{ME} \times \mathrm{A} \times \mathrm{P}^{2}-0.012 \\
(\mathrm{SD} 2.4) & (\mathrm{SD} 5.54) \quad(\mathrm{SD} 0.066) & (\text { SD } 0.415) \\
& \text { Residual SD } 0.121 ; r^{2} 0.93,
\end{array}
$$

or for TM2 and TH2 milks:

$$
\begin{array}{clc}
\mathrm{NF}=12.3 \times \mathrm{ME} \times \mathrm{P}-15.6 \times \mathrm{ME} \times \mathrm{P}^{2}-0.383 \times \mathrm{ME} \times \mathrm{A} \times \mathrm{P}^{2}-0.488 \\
(\mathrm{SD} \mathrm{16)} & (\mathrm{SD} 4.1) & (\mathrm{SD} 0.073) \\
& \text { Residual SD 0.159; } r^{2} 0.89 .
\end{array}
$$

In 2-week-old Ile de France pre-ruminant male lambs, $\mathrm{N}$ balances were not affected by tricaproin inclusion (Table 5), but an increase of $25 \%$ in digestible $\mathrm{N}$ intake led to a significantly higher $(P<0.05)$ NF $(+8.9 \%$ in group $\mathrm{CH} 2$ compared with group $\mathrm{CM} 2$, or $+9.8 \%$ in group TH2 compared with group TM2). In 3- and 4-week-old Ile de France lambs, $\mathrm{N}$ balances were not altered either by inclusion of tricaproin intake or by increase in protein concentration. 


\section{$N$ and energy balance between birth and the 3rd week (trial 2)}

For the whole $21 \mathrm{~d}$ balance period, tricaproin inclusion in the diet significantly $(P<0 \cdot 01)$ increased protein concentration in newly formed tissues, from $485 \mathrm{~g} / \mathrm{kg}$ (CM2 and $\mathrm{CH} 2$ milks) to $535 \mathrm{~g} / \mathrm{kg}$ (TM2 and TH2 milks), and conversely reduced lipid content of newly formed tissues from 515 to $465 \mathrm{~g} / \mathrm{kg}$ (Table 6). However, the relation between protein- and lipid-energy deposition (PF and LF) and ME intake was not significantly altered by tricaproin inclusion or by protein concentration. The total data led to the following relation, each variable being related to metabolic body-weight $\left(\mathrm{W}^{\mathbf{0} \cdot 75}\right)$ :

$$
\begin{aligned}
& \mathrm{ME}\left(\mathrm{kJ} / \mathrm{kg} \mathrm{W}^{0.75}\right)=1.92 \mathrm{PF}\left(\mathrm{kJ} / \mathrm{kg} \mathrm{W}^{0.75}\right)+0.94 \mathrm{LF}\left(\mathrm{kJ} / \mathrm{kg} \mathrm{W}^{0.75}\right)+553 \\
& \text { (SD 0.55) (SD 0.22) } \\
& \text { Residual SD } 57 \cdot 3 ; r^{2} 0 \cdot 72 \text {. }
\end{aligned}
$$

According to this relation, energy efficiency for tissue deposition was $0 \cdot 693,0.698,0.672$ and 0.673 for milks $\mathrm{CM} 2, \mathrm{CH} 2, \mathrm{TM} 2$ and $\mathrm{TH} 2$ respectively, and daily maintenance requirement $\left(\mathrm{ME}_{\mathrm{m}}\right)$ amounted to $553 \mathrm{~kJ} / \mathrm{kg}$ body-weight ${ }^{0.75}$.

\section{DISCUSSION \\ Accuracy of $N$ balances}

In trial 2, $\mathrm{N}$ retention was obtained in two ways: three consecutive periods of 1-week $\mathrm{N}$ balance determinations, or 3-week $\mathrm{N}$ retention estimated by the comparative slaughter technique. When compared (Fig. 1), both sets of values were closely correlated $(r 0.94)$, the slope of the regression of the $\mathrm{N}$ balance to the $\mathrm{N}$ retention being 0.98 (SD 0.08 ). In contrast to the results obtained by Liebenberg \& van der Merwe (1974) in the calf, $\mathrm{N}$ balances are thus quite reliable, irrespective of protein concentration.

However, $\mathrm{N}$ balance results were about $6.7 \mathrm{~g} \mathrm{~N}$ lower than $\mathrm{N}$ retention from slaughter values. This difference may arise from an error in the estimation of initial body $\mathrm{N}$ content, since Sykes \& Field (1972) found a body water content in Scottish Blackface lambs slaughtered $6 \mathrm{~h}$ after birth to be $11 \%$ lower than that of the lambs we studied (Villette \& Aurousseau, 1981). This discrepancy comes from the fact that within a few hours after birth, the newborn lambs lose weight by evaporation of amniotic liquid covering the wool and by respiratory exchange. Since the $\mathrm{N}$ balances were initiated $1-3 \mathrm{~d}$ after birth, a $9 \mathrm{~g}$ maximum error in the initial body $\mathrm{N}$ content of the lambs is possible, which would produce close similarity between the two sets of values.

\section{Maximum $N$ balance}

Unsupplemented milks. We used a relation which took into account individual variations of protein concentration, of level of intake and of age and weight of the lambs and, therefore, was suitable for describing continuous variations of net protein utilization as affected by variations of any one of these factors. In fact, the present study applies to a wide range of ages and weights of lambs (1-5 weeks and 2-12 kg body-weight) and to a wide range of ME intakes $(1 \cdot 2-7.7 \mathrm{MJ} / \mathrm{d})$. Only two levels of protein $(231-329 \mathrm{~g}$ protein $/ \mathrm{kg} \mathrm{DM})$ were used, but they were applied to 2- and 5-week-old lambs in trial 1, to 1-, 2- and 3-week-old lambs in trial 2, and to 2- and 4-week-old lambs in trial 3. The lambs showed different $\mathbf{N}$ requirements at the different ages, so that the combination of the whole set of data led to a mathematical analysis of the effects of four (trials 1 and 3) or six (trial 2) levels of protein, which explains the quadratic effect observed. This quadratic effect of protein concentration 


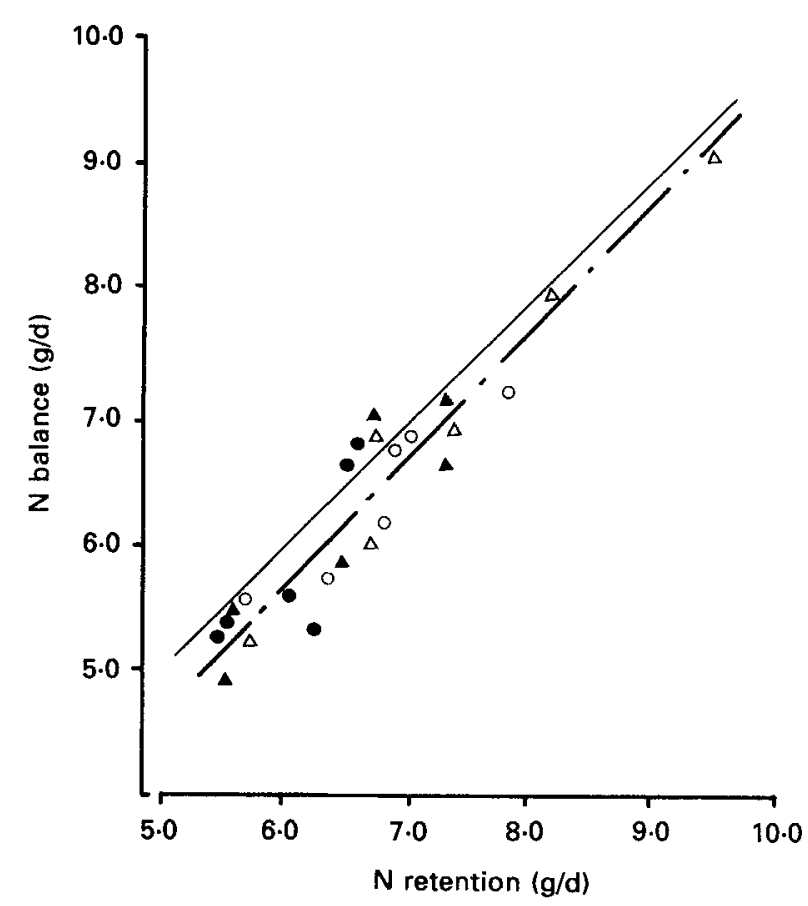

Fig. 1. Relation between 3 week nitrogen balance (obtained in metabolic crates) and $\mathbf{N}$ retention (according to the slaughter technique) obtained in twenty-four pre-ruminant male lambs given milks supplemented with lysine and methionine. (O), CM2, tallow-coconut oil, $233 \mathrm{~g}$ protein $/ \mathrm{kg}$ dry matter (DM); (O), TM2, tallow-coconut oil-tricaproin, $231 \mathrm{~g}$ protein $/ \mathrm{kg} \mathrm{DM} ;(\mathbf{A}), \mathrm{CH} 2$, tallow-coconut oil, $300 \mathrm{~g}$ protein $/ \mathrm{kg} \mathrm{DM} ;(\triangle)$, TH2, tallow-coconut oil-tricaproin, $301 \mathrm{~g}$ protein $/ \mathrm{kg} \mathrm{DM}$. Solid line illustrates the equality between $\mathrm{N}$ balance and $\mathrm{N}$ retention and interrupted line is the actual relation between the two sets of data.

enabled us to assess the effects of age on protein concentration where there is a maximum protein deposition, i.e. $P_{\max }$ which is the protein value where the slope of the derivative of the quadratic equation is nil. From eqn (1), one obtains:

$$
\mathrm{P}_{\max }=\frac{(114+11) \times 10^{2}}{(34 \cdot 6(\mathrm{SD} 5 \cdot 0))+(0 \cdot 79(\mathrm{SD} 0 \cdot 08)) \times \mathrm{A}}
$$

$\mathrm{P}_{\max }$ is thus determined with an uncertainty of about $25 \%$, which is in fact related to individual variations at a given age and individual variations of rate of variation in degree of maturity. The protein requirements $\left(P_{\max }\right)$ of the lambs would thus, according to eqn (1), decrease from 320 to 300 and $285 \mathrm{~g}$ protein/ $\mathrm{kg}$ DM respectively in 2-, 3- and 4-week-old lambs.

The values calculated from these relations were in good agreement with previous findings on the effects of protein intake on $\mathrm{N}$ retention (Walker \& Faichney, 1964; Walker \& Cook, 1967; Walker \& Norton, 1971; Chiou \& Jordan, 1973; Black \& Griffiths, 1975). When higher protein contents are used, protein deposition decreases, as observed in 3- (Table 3) to 5- (Table 2) week-old Limousin lambs and as described by Dove et al. (1977b). Aurousseau (1986) obtained identical results in another experiment on Romanov $x$ Limousin crossbred lambs where three levels of protein concentration in the milk were compared. The protein value for which there was maximum $\mathrm{N}$ retention was not affected by 


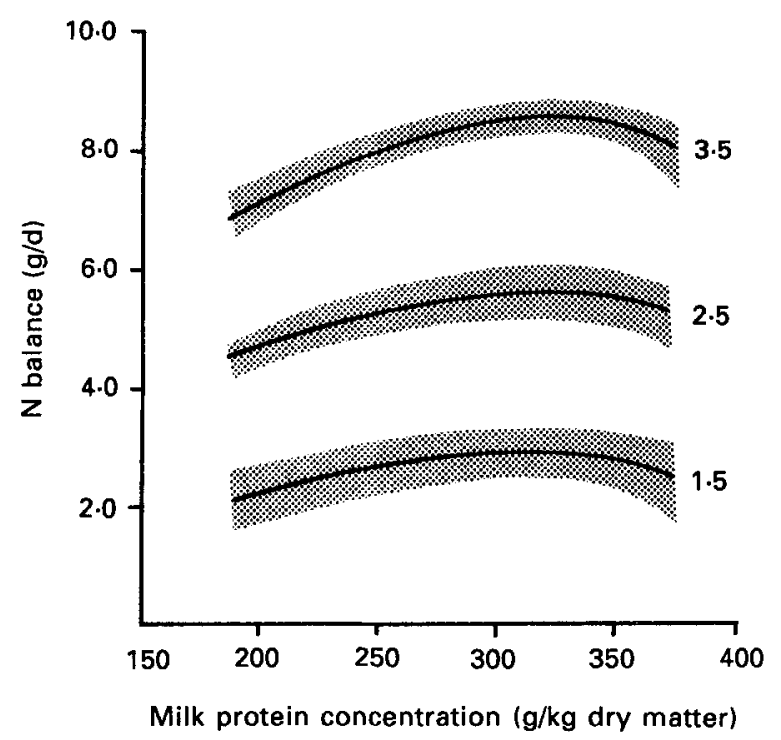

Fig. 2. Effect of interaction between metabolizable energy intake $(1.5,2.5$ and 3.5 times maintenance energy requirement) and milk protein concentration on nitrogen balance (图 standard deviation of mean) in preruminant male Limousin lambs of $4 \mathrm{~kg}$ body-weight given tallow-coconut-oil-containing milk without lysine and methionine supplementation.

the level of feeding of the lambs (Fig. 2), which is at variance with the findings of Chiou \& Jordan (1973). Both features can be explained by the fact that energy supplements lead to an increase in protein synthesis similar to the increase in protein deposition, whilst protein supplements lead to an increase in protein synthesis up to four times the increase in protein deposition, and thus result in higher energy expenditures (Reeds et al. 1982). Some energy may also be dissipated by urea synthesis and excretion (Martin \& Blaxter, 1964).

Lysine and methionine supplementation. The previous findings were limited to a range of protein concentrations from 230 to $330 \mathrm{~g} / \mathrm{kg} \mathrm{DM}$, and separate trials were used to study $\mathrm{N}$ balance in non-supplemented or supplemented milks. Nevertheless, bearing in mind that further studies are necessary to obtain a more precise value from a wider range of protein concentrations than that used here, it is clear that lysine and methionine supplementation decreased the protein value $\left(\mathrm{P}_{\max }\right)$ that was required for maximum $\mathrm{N}$ retention. The value of $P_{\max }$ thus decreased according to eqn (3) from 310 to $250 \mathrm{~g}$ protein $/ \mathrm{kg} \mathrm{DM}$ in 1- and 2week-old lambs respectively. The value obtained in 3-week-old lambs $(190 \mathrm{~g}$ protein $/ \mathrm{kg}$ DM), being out of the range of protein concentrations used in the experiment, needs to be reassessed. Although energy efficiency is not altered in lambs of $10 \mathrm{~kg}$ live weight (Colebrook \& Black, 1981), lysine and methionine supplements, in the rat, do lower tissue lipid content (Kurup et al. 1983), as lysine does by itself (Thapar \& Singh, 1983), and so may favour lipid energy utilization for the synthesis of ATP, leading to either a greater $\mathrm{N}$ balance or to a greater $\mathrm{N}$ turnover and an increased energy expenditure. These results could explain why protein deposition and growth (Theriez et al. 1977) did not increase when apparent methionine needs were met (Patureau-Mirand \& Theriez, 1977). With the usual protein value of $250 \mathrm{~g} / \mathrm{kg} \mathrm{DM}$, methionine suppementation increased $\mathrm{N}$ retention in younger lambs, but from the 3 rd week excess $\mathrm{N}$ intake counteracted the previous positive effect. Thus a positive effect of methionine supplementation has been observed only with 
low protein concentrations (Walker, 1975; Walker \& Kirk, 1975), whilst a positive effect of essential amino acid (EAA) supplementation is observed for a concentration in the milk of $414 \mathrm{mg} \mathrm{EAA} / \mathrm{g}$ crude protein when protein is $259 \mathrm{~g} / \mathrm{kg}$ DM or for a concentration in the milk of $512 \mathrm{mg} \mathrm{EAA} / \mathrm{g}$ crude protein when protein is $209 \mathrm{~g} / \mathrm{kg}$ DM( Dove et al. 1977 a, b).

Tricaproin intake. In both trials 1 and 2, tricaproin inclusion in the fat (192-373 g caproic $\mathrm{acid} / \mathrm{kg}$ fat), in addition to the medium-chain fatty acids already afforded by coconut oil (about $0 \cdot 2 \mathrm{~g}$ caproic acid, 50-64 g caprylic and capric acids, 199-256 g lauric and myristic acids $/ \mathrm{kg}$ fat) led to a significant increase in protein deposition (Tables 2 and 3).

Caproic acid absorption in sheep is followed by an increase in plasma insulin (Ambo et al. 1973; Said et al. 1986 b). If such an increase in insulin secretion occurs in the young preruminant lamb, it is followed by a greater thyroxin secretion (Koppel et al. 1982). The former favours muscle protein synthesis through an effect on ribosomal activity, and the latter through an effect on protein elongating activity (Millward et al. 1983).

Caproic acid absorption from the ruminant digestive tract increases plasma glucose (Ash et al. 1959; Yamdagni et al. 1968; Said et al. 1986 ; Ambo et al. 1973). However, glucose uptake by the muscle is relatively low, even in the presence of insulin (Prior \& Smith, 1982). However, a higher concentration of caproic acid in milk is also followed by a higher concentration of ketone bodies and free fatty acids in plasma which can provide energy to the muscle efficiently (Ash et al. 1959; Yamdagni et al. 1968; Ambo et al. 1973). Finally, in addition to a better efficiency of NF in the lambs given supplements of caproic acid, the protein concentration which gave maximum $\mathrm{N}$ balance was higher than that for control milk, i.e. about 440 and $320 \mathrm{~g}$ protein $/ \mathrm{kg}$ DM in 3- and 5-week-old Limousin lambs respectively in the case of unsupplemented milks, and 350,300 and $210 \mathrm{~g}$ protein $/ \mathrm{kg} \mathrm{DM}$, in 1-, 2- and 3-week-old Limousin lambs respectively in the case of milks supplemented with lysine and methionine. However, the values obtained with tallow-coconut oil-tricaproin milk not supplemented with methionine and lysine are out of the range of protein concentrations used and should be reassessed.

It was noteworthy that NF in the tissues of Ile de France lambs given lysine and methionine-supplemented milk, which was higher than that in Limousin lambs, was not affected by inclusion of tricaproin supplements in the milk. In fact, much higher protein concentrations in the milk were required in the Ile de France lambs to achieve maximum protein retention, i.e. about 370 and $270 \mathrm{~g}$ protein/ $\mathrm{kg} \mathrm{DM}$ in 2- and 4-week-old Ile de France lambs respectively. Apparently the energy needs were entirely met by the lysine- and methionine-supplemented milks. As caproic acid is related to a high rate of lipid catabolism in the liver (Berry et al. 1983), we can assume that the rate of catabolism of long- and medium-chain fatty acids is already high in Ile de France lambs given milks supplemented with lysine and methionine.

\section{ME efficiency}

The energy costs of protein and lipid synthesis were in the range of previous determinations in growing animals (Buttery \& Boorman, 1976; Kielanowski, 1976), but maintenance energy expenditures were $10 \%$ higher than those reported previously (Walker \& Norton, 1971; Chiou \& Jordan, 1973). This is not unexpected since high levels of energy expenditure as heat are observed after birth (Alexander et al. 1970; Vermorel et al. 1984). However, previous workers have observed an even higher level of $\mathrm{ME}_{\mathrm{m}}$ in 1-week-old lambs, whilst others have observed a lower level in 3-week-old lambs (Walker \& Norton, 1971; Chiou \& Jordan, 1973). A decrease in $\mathrm{ME}_{\mathrm{m}}$ with increasing age of lambs has been confirmed (Degen \& Young, 1982): energy balance at 1,2 and 3 weeks would have been useful to take this into account. The increased $\mathrm{N}$ retention in the young preruminant lamb, increased at the 
expense of lipid deposition without altered efficiency of ME utilization, has already been reported (Aurousseau et al. 1983a, 1984). This can be explained by the fact that protein synthesis per se accounts for only $25 \%$ of energy expenditure above maintenance in the growing animal (Reeds et al. 1982), ion transport being another major source (Milligan \& Summers, 1986).

\section{REFERENCES}

Alexander, G., Bell, A. W. \& Williams, D. (1970). Biology of the Neonate 15, 198-210.

Ambo, K., Takahashi, H. \& Tsuna, T. (1973). Journal of Agricultural Research 24, 54-62.

Ash, R. W., Pennington, R. J. \& Reid, R. S. (1959). Biochemical Journal. 71, 9P.

Aurousseau, B. (1971). Annales de Biologie Animale, Biochimie, Biophysique 12, 263-280.

Aurousseau, B. (1984). Annales de Zootechnie 33, 219-234.

Aurousseau, B. (1986). Diabéte et Métabolisme 12, 107-108.

Aurousseau, B., Perez, J. M., Bouvier, J. C. \& Vermorel, M. (1978). Annales de Biologie Animale, Biochimie, Biophysique 18, 1107-1115.

Aurousseau, B., Vermorel, M. \& Bouvier, J. C. (1983a). Reproduction, Nutrition, Développement 23, $587-597$.

Aurousseau, B., Vermorel, M. \& Bouvier, J. C. (1984). Reproduction, Nutrition, Développement 24, $265-279$.

Aurousseau, B., Vermorel, M. \& Theriez, M. (1983 b). Annales de Zootechnie 32, $441-458$.

Bachacou, J., Masson, J. P. \& Millier, C. (1981). Manuel de la Programmathèque Statistique AMANCE 81, pp. 209-270. Paris: INRA.

Berry, M. N., Clark, D. G., Grivell, A. R., Wallance, P. G. (1983). European Journal of Biochemistry 131, 205-214.

Black, J. L. \& Griffiths, D. A. (1975). British Journal of Nutrition 33, 399-413.

Buttery, P. J. \& Boorman, K. N. (1976). In Protein Metabolism and Nutrition, pp. 197-206. [D. J. A. Cole, K. N. Boorman, P. J. Buttery, D. Lewis, R. J. Neale and H. Swan, editors]. London: Butterworths.

Chenat, M. C., Aurousseau, B. \& Vermorel, M. (1976). Annales de Biologie Animale, Biochimie, Biophysique 16, 603622 .

Chiou, P. W. S. \& Jordan, R. M. (1973). Joumal of Animal Science 37, 581-587.

Colebrook, W. F. \& Black, J. L. (1981). Animal Production 33, 253-258.

Degen, A. A. \& Young, B. A. (1982). Journal of Animal Science 54, 353-362.

Demarne, Y., Epo, N. \& Flanzy, J. (1978). Archives Internationales de Physiologie et de Biochimie 86, 25-35.

Dove, H., Pearce, G. R. \& Tribe, D. E. (1977a). Australian Journal of Agricultural Research 28, $917-932$.

Dove, H., Pearce, G. R. \& Tribe, D. E. (1977b). Australian Journal of Agricultural Research 28, 933946.

Kielanowski, U. (1976). In Protein Metabolism and Nutrition, pp. 207-215 [D. J. A. Cole, K. N. Boorman, P. J. Buttery, D. Lewis, R. J. Neale and H. Swan, editors]. London: Butterworths.

Koppel, J., Kuchar, S., Mozes, S., Herzova, J. \& Boda, K. (1982). Hormone and Metabolic Research 12 , $631-633$

Kurup, G. M., Leelamma, S. \& Kurup, P. A. (1983). Indian Journal of Biochemistry and Biophysics 19 , 347-351.

Lavau, M. H. \& Hashim, S. A. (1978). Journal of Nutrition 108, 613-620.

Liebenberg, L. H. P. \& Van der Merwe, F. J. (1974). South African Journal of Animal Science 4, 21-26.

Martin, A. K. \& Blaxter, K. L. (1964). In Energy Metabolism of Farm Animals, pp. 83 91. [K. L. Blaxter, editor]. London and New York: Academic Press.

Milligan, L. P. \& Summers, M. (1986). Proceedings of the Nutrition Society 45, 185-193.

Millward, D. J., Bates, P. C., de Benoist, B., Brown, J. G., Cow, M., Halliday, D., Odedra, B. \& Rennie, M. J. (1983). In Protein Metabolism and Nutrition, pp. 69-96. [M. Arnal, R. Pion, and D. Bonin, editors]. ClermontFerrand: INRA.

Newport, M. J., Storry, J. E. \& Tuckley, B. (1979). British Journal of Nutrition 41, 85-93.

Patureau-Mirand, P. \& Theriez, M. (1977). Annales de Zootechnie 26, 287. (Abstr.)

Prior, R. L. \& Smith, S. B. (1982). Federation Proceedings 40, 2545-2549.

Reeds, P. J., Wahle, K. W. J. \& Haggarty, P. (1982). Proceedings of the Nutrition Society 41, 155-158.

Said, A., Mueller, I., Kolb, E., Gruender, G., Schmidt, V., Schineff, C., Gottschild, C. \& Vallentin, G. (1986a). Archiv für Experimentelle Veterinärmedizin 40, 183-194.

Said, A., Mueller, I., Kolb, E., Gruender, G., Schmidt, U., Schineff, C., Gottschild, C. \& Vallentin, G. (1986b). Archiv für Experimentelle Veterinärmedizin 40, 195-205.

Snedecor, G. W. \& Cochran, W. G. (1956). Statistical Methods. p. 85. Ames, Iowa: Iowa State College Press.

Sykes, A. R. \& Field, A. C. (1972). Journal of Agricultural Science, Cambridge. 78, 119-125.

Thapar, M. \& Singh, S. (1983). Zeitschrift für Ernährungswissenschaften 22, 27-33.

Theriez, M., Patureau-Mirand, P. \& Molenat, G. (1977). Annales de Zootechnie 24, 297-313.

Tissier, M., Bechet, G. \& Molenat, G. (1975). Annales de Zootechnie 24, 595-602. 
Vermorel, M. \& Aurousseau, B. (1970). In Energy Metabolism of Farm Animals pp. 185-188 [A. Schurch and C. Wenk, editors]. Zurich: Juris Druck Verlag.

Vermorel, M., Bouvier, J. C., Bonnet, Y. \& Fauconneau, G. (1973). Annales de Biologie Animale, Biochimie, Biophysique 13, 659-681.

Vermorel, M., Dardillat, C., Vernet, J., Saido, S. \& Demigne, C. (1984). In Physiologie et Patologie Périnatales chez les Animaux de Ferme [R. Jarrige, editor]. Paris: INRA.

Villette, Y. \& Aurousseau, B. (1981). Annales de Zootechnie 30, 285-298.

Walker, D. M. (1975). Australian Journal of Agricultural Research 26, 681-688.

Walker, D. M. \& Cook, L. J. (1967). British Journal of Nutrition 21, 237-256.

Walker, D. M. \& Faichney, G. J. (1964). British Journal of Nutrition 18, 295-306.

Walker, D. M. \& Kirk, R. D. (1975). British Journal of Nutrition 26, 673-679.

Walker, D. M. \& Norton, B. W. (1971). British Journal of Nutrition 26, 15-29.

Yamdagni, S., Schultz, L. H. \& Radloff, H. D. (1968). Journal of Dairy Science 51, 1094-1097. 